\title{
ESTOMATITES AFTOSAS: UMA REVISÁO DA LITERATURA
}

\author{
APHTHOUS STOMATITIS: A REVIEW OF THE LITERATURE
}

\author{
Layza Kowalski ${ }^{1}$, Bianca Ávila de Matos ${ }^{1}$, Camila Kupski ${ }^{1}$, Andressa Rodrigues \\ Pagno $^{1}$ \\ ${ }^{1}$ Universidade Regional Integrada do Alto Uruguai e das Missóes, URI; Santo Ângelo, RS, \\ Brasil.
}

\section{RESUMO}

As estomatites aftosas afetam em torno de $20 \%$ da população, ocorrem predominantemente na população jovem, em sua maioria mulheres, causando transtornos como dificuldade na alimentação e na fala. Algumas estomatites aftosas, consideradas menores, geralmente, desaparecem sem a necessidade de tratamento. Mas, se houver muita dor, pode-se recorrer a tratamentos sintomáticos. Dessa forma, o presente trabalho objetivou caracterizar os fatores desencadeantes, bem como, possíveis tratamentos das ulceraçôes. A metodologia se deu através da revisão bibliográfica utilizando as bases de dados Scientific Electronic Library Online, US National Library of Medicine National Institutes of Health, e na Agência Nacional de Vigilância Sanitária, na busca e seleção de artigos científicos. O estudo aponta possíveis causas e tratamentos para estomatites, destacando medicamentos isentos de prescriçáo médica e plantas medicinais eficazes no alívio da dor e inflamação.

Descritores: Cavidade oral, estomatite aftosa, ulceração aftosa.

\section{ABSTRACT}

Aphthous stomatitis affects around $20 \%$ of the general population, occurring predominantly in the young population, mostly women, causing disorders such as difficulty in eating and speaking. Some aphthous stomatitis, considered minor, usually disappear without the need for treatment. But if there is a lot of pain or difficulties related to it, you can resort to symptomatic treatments. Thus, the present study aimed to characterize the triggering factors as well as possible ulcer treatments. The methodology was based on the bibliographic review using the Scientific Electronic Library Online, US National Library of Medicine National Institutes of Health, and Agência Nacional de Vigilância Sanitária databases, in the search and selection of scientific articles. The study points to possible causes and treatments for stomatitis, highlighting MIP's and herbal remedies effective in relieving pain and inflammation.

Descriptors: Mouth, aphthous stomatitis, aphthous ulceration. 


\section{INTRODUÇÃO}

O termo grego "Aphtay”, é creditado a Hipócrates (460 a 370 AC), e é dele que vem a palavra afta, a qual significa queimar ${ }^{1}$. As aftas bucais ou estomatites aftosas apresentamse por lesôes vesiculares, de origens multifatoriais, comuns e dolorosas, caracterizadas por descamações da superfície do epitélio oral, com comprometimento sistêmico ausente e funcionalidade comprometida ${ }^{2}$. Conforme a intensidade e a persistência dessa situaçáo, essas lesões podem se manifestar de forma recidivante e passam a ser denominadas Úlceras Aftosas Recorrentes (UAR) ou Estomatite Aftosa Recorrente (EAR) ${ }^{3}$.

O transtorno afeta cerca de $20 \%$ da população, ocorre predominantemente na população jovem, em sua maioria mulheres, o que causa transtornos como dificuldade na alimentação e na fala. Subdividem-se em três classes, aftas menores, aftas maiores e herpetiforme, com diferentes características de diâmetro, duração e podendo ter cicatrizes ou não ${ }^{4,5}$. Sua origem é desconhecida, e possui evidências que indicam relação com o sistema imunológico, aspectos hereditários, traumas, fatores psicológicos, ingesta de alimentos, deficiência da vitamina B12, deficiência de ácido fólico e de ferro, assim como níveis baixos de vitaminas $\mathrm{A}, \mathrm{E}$ e $\mathrm{C}^{6-10,1,11}$.

Algumas estomatites aftosas, consideradas menores, geralmente, desaparecem sem a necessidade de tratamento. Mas se houver muita dor, pode-se recorrer a tratamentos dos sintomas. Não há uma terapêutica estabelecida, porém, são adotadas medidas simples como higiene bucal adequada e cuidados de âmbito nutricional, e métodos farmacológicos, que podem ajudar a amenizar o desconforto ${ }^{5}$.

Nesse sentido, alguns dos medicamentos isentos de prescrição (MIPs), possuem eficácia comprovada, e podem ser prescritos pelo farmacêutico, tornando-se uma alternativa econômica, segura e responsável para o tratamento das estomatites aftosas 5,2,7. Tais medicamentos são de uso tópico, e são encontrados na forma de colutórios, pasta bucal e pó, e podem ser associados ou não a analgésicos orais de ação sistêmica ${ }^{12-16}$. Estes MIPs são, geralmente, antissépticos orais e antissépticos buco-faríngeos. Ainda, é possível o uso de plantas medicinais para minimizar os efeitos causados pelo transtorno ${ }^{18-20}$.

Pela relevância do tema, o presente trabalho tem como objetivo descrever as características e os fatores desencadeantes das estomatites aftosas, bem como, possíveis tratamentos das lesóes causadas pelo transtorno.

\section{METODOLOGIA}

Trata-se de uma revisão bibliográfica, com investigação exploratória de estudos sobre estomatites aftosas, nas bases de dados Scientific Electronic Library Online (Scielo), US National Library of Medicine National Institutes of Health (PUBMED), e na Agência 
Nacional de Vigilância Sanitária (ANVISA). Os descritores utilizados, em língua portuguesa e inglesa, foram: cavidade oral, estomatite aftosa, ulceração aftosa (DeCS Descritores em Ciências da Saúde). Os artigos foram selecionados de acordo com o título e o resumo, onde se destacava o tema do estudo.

\section{REVISÃO}

\section{Caracterização da doença}

As estomatites aftosas apresentam inicialmente uma coloração avermelhada, a qual rapidamente sofre necrose. Há modificação da coloraçáo interna, tornando o centro esbranquiçado. As ulcerações possuem aspectos clínicos ovais ou arredondados, ocorrem na língua, bochecha, lábios, palato mole e duro, gengiva, faringe e assoalho da boca. $\mathrm{O}$ período de agravo é entre o $3^{\circ}$ e $4^{\circ}$ dia, dificultando a fala e alimentação ${ }^{10}$.

Clinicamente podem ser classificadas conforme seu tamanho, forma e localização. Suas manifestaçóes estão relacionadas quanto a formação de cicatrizes, e podem ser divididas em três tipos: aftas menores, aftas maiores e herpetiforme ${ }^{5}$. As aftas menores têm maior prevalência dentre as demais, ocorrem em cerca de $80 \%$ dos casos. Possuem pequeno diâmetro, cerca de 1 a $10 \mathrm{~mm}$, com presença de ulceraçóes múltiplas, cerca de uma a cinco úlceras na cavidade oral, localizadas nas zonas moles da mucosa, costumam curar-se em 10 a 14 dias, de forma espontânea e sem deixar cicatrizes ${ }^{21,10,5}$.

As aftas que apresentam maior severidade, porém menor prevalência são aquelas classificadas como maiores, as quais apresentam formas circulares e em alguns casos ovais, com diâmetro de 1 a $3 \mathrm{~cm}$. Podem aparecer em qualquer regiáo da mucosa oral, com maior incidência nos lábios e palato mole. São consideradas extremamente dolorosas e persistentes, com duração em torno de semanas a meses e resultam em cicatrizes ${ }^{21,10,5}$.

Já, a herpetiforme apresenta rara prevalência, 5 a 10\% dos pacientes são afetados. É dolorosa, e caracterizada por lesóes múltiplas com pequeno diâmetro (1 a $3 \mathrm{~mm}$ ), que coalescem, formando úlceras maiores com bordas irregulares. Levam de 7 a 30 dias para curar, e podem acometer qualquer região da cavidade oral ${ }^{7,5}$.

\section{Fatores desencadeantes da estomatite aftosa}

Em relação aos fatores que podem desencadear o transtorno, a teoria do complexo autoimune é a hipótese mais significativa e aceita como causa desencadeante das estomatites aftosas. Há evidências que apontam para a participação do sistema imune, através da mediação dos linfócitos $T$, que culmina na lise das células epiteliais da mucosa oral ${ }^{6,7}$. Ainda, confirmando a relaçáo entre as estomatites aftosas recorrentes e a imunidade do paciente, aqueles pacientes imunodeprimidos, como pacientes com 
Síndrome da Imunodeficiência Adquirida (AIDS), pacientes com doença de Crohn, doença de Behçet e síndrome de Sweet, estáo mais propensos ao acometimento de úlceras orais ${ }^{1,7}$. Contudo, por não apresentar seus efeitos de forma semelhante na população, a etiologia ainda é desconhecida 5 .

Existem outros fatores descritos na literatura que explicam o aparecimento das aftas, dentre eles os aspectos hereditários. Há 50\% de chance de herdar características de propensão às aftas quando há histórico positivo de um dos pais para tal propriedade. Sugerindo assim, que algumas pessoas são geneticamente predispostas a sofrer ulceraçáo oral, uma vez que, as lesões têm sido observadas em membros da mesma família ${ }^{8,9}$. Essa correlação pode ser explicada pela forte associação entre as moléculas implicadas no controle genético da resposta imune, como o HLA-A33 e o HLA-B35, com a etiologia e a ocorrência das estomatites aftosas recorrentes do tipo menor ${ }^{7}$.

Ainda, há tendência para o desenvolvimento de estomatites aftosas em sítios submetidos a traumas frequentes na cavidade oral. As causas mais comuns para o traumatismo são a escovaçáo dentária agressiva, o uso do fio dental, tratamentos dentários e áreas da boca suscetíveis a freio auto imposto (mordida na bochecha) ${ }^{10,1}$.

O estudo de Rioboo (2011) demonstrou que fatores psicológicos, como estresse mental, parecem precipitar a aparição da doença. Tal pesquisa mediu níveis de cortisol na saliva e no soro de pacientes com estomatites recorrentes, e observaram concentraçôes superiores de cortisol, sugerindo que o estresse e seu efeito no sistema imunológico seja uma possível causa ${ }^{11}$.

Há, também, descrições de que a ingestão de alguns alimentos, como leite de vaca, chocolate, café, entre outros, bem como, alterações endócrinas, tais como ciclo menstrual e período pós-menopausa, mesmo sem explicação definitiva do mecanismo para tais fenômenos, têm sido associados e descritos como possíveis desencadeadores do aparecimento das ulceraçóes ${ }^{10}$.

A deficiência da vitamina B12 aparece como maior associação a episódios de estomatites afotsas, seguido por deficiência de ácido fólico, deficiência de ferro e níveis baixos de vitaminas $\mathrm{A}, \mathrm{E}$ e C ${ }^{11}$. A deficiência da vitamina $\mathrm{B} 12$ é fundamental para crescimento e divisão celular, e produção de glóbulos vermelhos, na cavidade bucal a deficiência da mesma está relacionado com ardência bucal ${ }^{11}$.

O ácido fólico quando está deficiente promove uma lenta degeneração das células da mucosa, causando modificações gastrintestinais, atrofia da mucosa bucal e favorece o desenvolvimento das aftas. O ferro está relacionado com sistema imunológico o seu déficit resulta sobre mecanismos imunes celulares ${ }^{22}$. 


\section{Abordagem diagnostica}

O diagnóstico da estomatite aftosa se dá, essencialmente, por anamnese a qual orientará a necessidade ou não de uma investigação complementar. Os sintomas típicos são queimação ou desconforto na mucosa oral um a dois dias antes do aparecimento das úlceras. Os exames complementares devem ser reservados para casos mais extensos, atípicos e recorrentes. Sendo assim, o paciente deve ser o centro das açóes do profissional e integrado em um contexto epidemiológico e clínico. O algoritmo (Figura 1) proposto por Letsinger e colaboradores (2005) pode auxiliar a orientar a investigação diagnóstica das estomatites aftosas complexas recorrentes e a investigaçáo de cada uma das hipóteses 23.

Figura 1: Avaliação da aftose complexa.

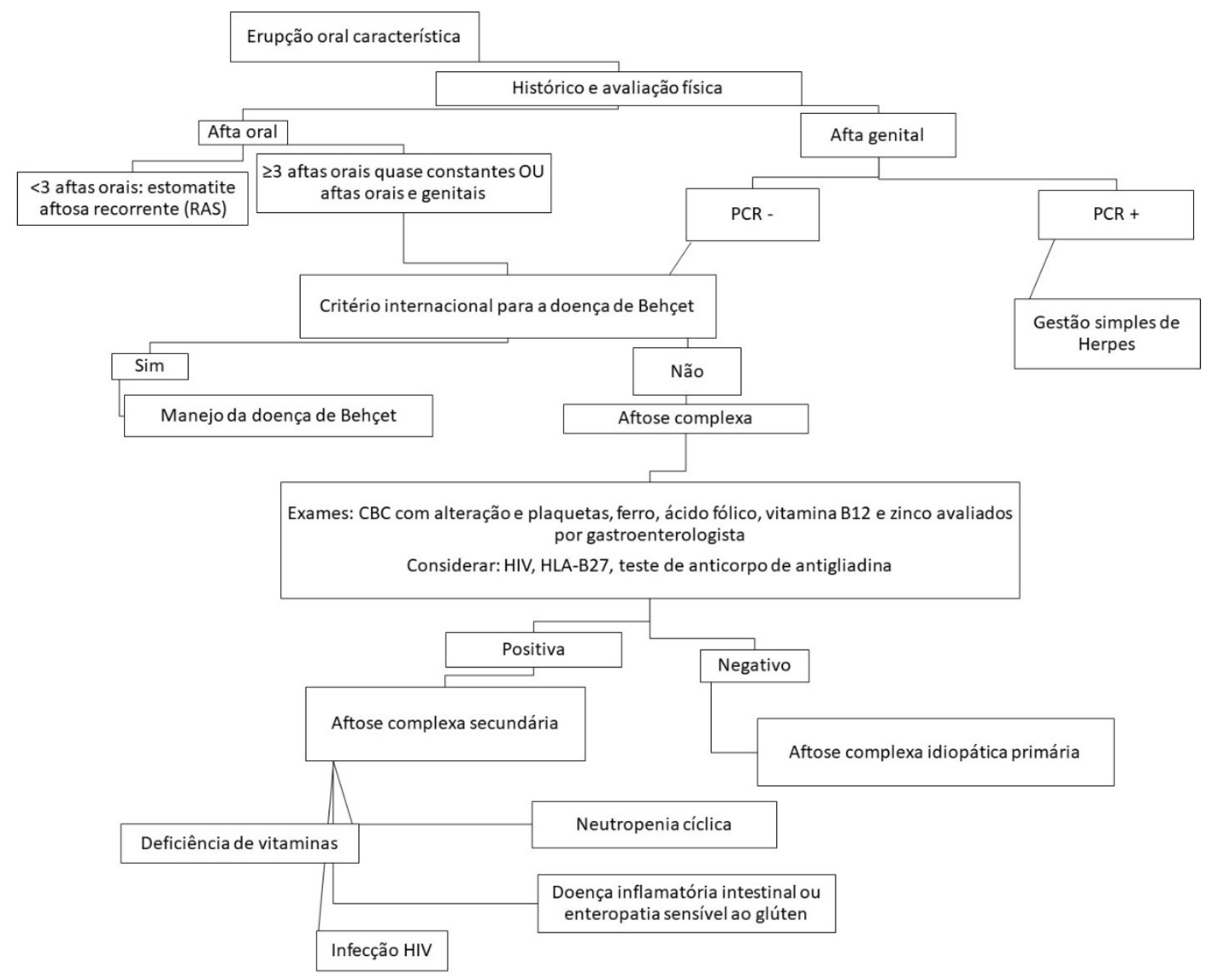

Fonte: OLIVEIRA, ARMD.

Conforme o esquema da figura 1, para se caracterizar erupções orais é necessário avaliar o exame físico e a história clínica do paciente. Quando há casos com prevalência inferior a três lesóes na cavidade oral, há a caracterização de estomatite aftosa recorrente. Nos casos de prevalência igual ou superior a três aftas devem-se avaliar critérios para a 
classificação ou não da doença de Behçet, a qual é caracterizada como inflamação rara nos vasos sanguíneos ${ }^{23}$.

Obtendo resultado positivo para doença de Behçet, o médico faz o manejo da doença. Em caso de resultado negativo, realiza-se exames para avaliar o estado de saúde do paciente, avaliando o resultado do hemograma completo, níveis de ferro, avaliação do ácido fólico, vitaminas B12 e zinco, realizados por um gastroenterologista, com o intuito de averiguar hipóteses causadoras das lesões. Considera-se também doenças como HIV, HLA-B27 e doença celíaca ${ }^{23}$.

Em caso de negativo todos os testes, trata-se de uma estomatite aftosa complexa idiopática primária, ou seja, sem causa certa ou conhecida e em caso positivo de algum dos exames, faz-se o tratamento adequado para a enfermidade diagnosticada ${ }^{23}$.

Quanto a atuação do farmacêutico em caso de aftas, esta se dá pela anamnese, onde o profissional avalia o caso do paciente e como proceder. Por exemplo, se o paciente possuir idade maior que 65 anos, este deve ser encaminhado ao médico, caso contrário, realiza-se algumas perguntas, como o tempo que se tem a afta, quantas e como se apresentam, em caso de resposta positiva para tempo superior a quinze dias e incidência superior a cinco aftas, encaminha-se o paciente ao médico, caso não se enquadre na situação citada acima, segue-se com o questionário a fim de excluir possíveis causas. Após a anamnese, e caso o farmacêutico não identificar a etiologia ocasionada pelo uso de anti-inflamatório ou enfermidades como por exemplo anemia e AIDS, segue-se para aconselhamento farmacêutico e seleção de medicamentos.

\section{Tratamentos}

Devido o pouco conhecimento acerca da etiologia das estomatites aftosas, não há tratamento estabelecido para a cura das lesóes, porém ao utilizar de terapias medicamentosas e tratamentos não farmacológicos, é possível reduzir a duração e promover a cicatrização das ulceraçóes; diminuir a dor, reduzindo a morbidade; fazer o manejo nutricional e controlar a doença, prevenindo a recorrência e/ou reduzindo a frequência ${ }^{5,1,7}$.

\section{Tratamentos náo medicamentosos e prevenção}

O tratamento não farmacológico é uma das primeiras alternativas em conjunto com o estágio da estomatite aftosa, ou seja, requer cuidados como: higiene bucal adequada utilizando escovas com cerdas macias, afim de diminuir a agressão bucal e consequentemente a dor, ingestão de alimentos suaves, para facilitar a alimentação, evitar alimentos picantes e quentes os quais podem intensificar a sensação de dor e fazer uso de enxaguatórios orais, que irão auxiliar no alivio da dor ${ }^{12}$. 
$\mathrm{O}$ pH bucal baixo possui uma correlação com aparecimento de aftas, isto ocorre devido a ingestão de alimentos ácidos, portanto, é necessário cuidado ao ingerir alguns alimentos como por exemplo as frutas cítricas e ácidas, tais como o limão, a laranja, o abacaxi e o kiwi que alteram o $\mathrm{pH}$ da boca e fazem com que a mucosa fique vulnerável a desenvolver aftas ou potencializá-las. Alimentos como batatas fritas e amendoins salgados também auxiliam no agravo da afta e na sensação de dor. Nozes e cajus são alimentos duros e acabam causando lesóes, o que favorece o desenvolvimento de aftas. O café, por ser uma bebida muito quente, potencializa a lesão na boca e assim favorece o aparecimento das mesmas ${ }^{24}$.

A prevenção é fundamental para que não ocorra o desenvolvimento de aftas. Algumas medidas podem auxiliar tais como: complementar a dieta com ingestáo de lisina que se encontra em alimentos como peixes, ovos, batata e frango e que combate aftas; consumir iogurte; restringir o estresse; praticar exercícios físicos; usar de escova de dente de cerdas macias; praticar mastigação lenta; consumir alimentos frios; evitar o cigarro, chicletes, balas e pastilhas; fazer uso de creme dentais e enxaguatórios que na sua formulação não contenham lauril sulfato de sódio e observar e analisar a ingestão de certos alimentos com o surgimento de aftas ${ }^{25}$.

\section{Tratamentos medicamentosos}

Os recursos terapêuticos são administrados tanto na forma sistêmica, quanto na forma tópica. Os medicamentos de uso tópico são considerados os de primeira escolha para o tratamento das ulceraçóes por serem mais seguros para o paciente, devido à menor ocorrência de eventos adversos. Sabe-se que há descamação acelerada do epitélio oral, com alteraçôes na flora da cavidade oral, o que pode conduzir a inflamação da mesma, variando o tipo e a gravidade das ulceraçóes, dessa forma, o tratamento pode variar com o objetivo principal do alivio dos sintomas ${ }^{5}$. Alguns medicamentos isentos de prescriçáo que podem ser utilizados, por via tópica, no alívio da sintomatologia da estomatite aftosa.

\section{Albocresil $^{\oplus}$}

O Albocresil, nome comercial do princípio ativo policresuleno, apresenta forma farmacêutica de gel $(18 \mathrm{mg} / \mathrm{g})$ ou de solução concentrada $(360 \mathrm{mg} / \mathrm{g})$, e é utilizada para o tratamento tópico de aftas e nas inflamaçóes da membrana da mucosa oral e das gengivas $^{13}$.

O medicamento possui ação antisséptica, e pode apresentar: ação antimicrobiana para bactérias gram positivas e negativas, fungos e protozoários, pois em sua formulação há a presença do butilhidroxitolueno; alteração seletiva do tecido necrosado e do epitélio colunar; e ação hemostática através da coagulação proteína do sangue e intensa vasoconstrição ${ }^{19}$ 
Possui capacidade de desbridamento químico seletivo, ou seja, promove limpeza da lesão, removendo apenas o tecido inviável sem afetar o tecido vivo, reduzindo a contaminação bacteriana e promovendo cicatrização ${ }^{26,27}$.

Apresenta, também, ação hemostática por coagulação das proteínas do sangue e intensa vasoconstrição de vasos de pequeno calibre ${ }^{13}$. A ação homeostática é quando um agente mecânico que faz acessar o sangramento e/ou aumento da cascata de coagulaçáo sanguínea ${ }^{13,28,29}$. Suas propriedades coagulantes, juntamente com a sua acidez, conferem atividade antimicrobiana ao fármaco para Staphylococcus, Streptococcus e Cândida albicans, possuindo assim, amplo espectro para bactérias Gram positiva e Gram negativa, bem como, é eficaz conta alguns fungos. A ação antimicrobiana e o desbridamento são importantes agentes nos processos de cicatrização ${ }^{13,26,29}$.

\section{Flogoral $^{\oplus}$}

O Flogoral, tem como princípio ativo o cloridrato de benzidamina, que apresenta forma farmacêutica de colutório, e que é utilizado no tratamento de aftas e demais dores e inflamações que podem ocorrer na cavidade oral. Possui eficácia analgésica e anestésica local, atuando diretamente nas células do processo inflamatório, estabilizando as membranas celulares e reduzindo as prostaglandinas, a qual desempenham papel de mediadoras de processos inflamatórios. Seu acúmulo se dá nos tecidos inflamados e seus efeitos se manifestam somente naqueles órgãos patologicamente alterados ${ }^{14,15}$.

Na sua formulação há o álcool etílico que possui espectro de ação para bactérias e fungos, assim como o metilparabeno, utilizado na prevenção do crescimento e desenvolvimento de microrganismos ${ }^{15,18}$.

Sua permeação através das membranas é aumentada quando o pH está na faixa de 5 a 7,6, em que para valores superiores esta relação deixa de se verificar possivelmente, devido a uma diminuiçáo da solubilidade ${ }^{30,31}$.

\section{Albicon $^{\oplus}$}

Outra medida farmacológica eficaz é o Albicon em pó, para uso tópico, com efeito imediato, cerca de 15 a 30 segundos. O medicamento possui ação alcalinizante, diminuindo a acidez da cavidade oral, ação antisséptica e também ação anestésica. Deve ser aplicado diretamente sobre a afta, ou pode-se realizar gargarejos ou bochechos ${ }^{32}$.

A benzocaína atua como anestésico tópico, absorvido rapidamente através das mucosas, age diminuindo a permeabilidade aos íons sódio através da membrana neuronal. Esta ação inibe a despolarização da membrana neuronal, bloqueando a iniciação e a condução dos impulsos nervosos. 
Figura 4: Estrutura química da benzocaína $\left(\mathrm{C}_{9} \mathrm{H}_{11 \mathrm{~N}} \mathrm{O}_{2}\right)$

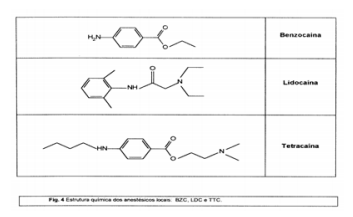

Fonte: PINTO 1998.

O bicarbonato de sódio, outro composto do Albicon, atua como alcalinizante, elevando o $\mathrm{pH}$ do meio, uma vez que reage com os íons de hidrogênio formando água e dióxido de carbono, auxiliando no combate aos fungos e microrganismos. O clorato de potássio apresenta efeito antisséptico e ação oxidante moderada ${ }^{18,14}$

\section{Tratamento com uso de plantas e medicamentos fitoterápicos}

O uso de plantas e medicamentos fitoterápicos é mundialmente utilizado, e considerado uma forma eficaz de atendimento primário à saúde. Suas ações terapêuticas são oriundas dos metabólitos secundários, os quais são compostos orgânicos, oriundos de rotas metabólicas especificas. No tratamento de estomatites aftosas pode-se citar a malva e a camomila como importantes fontes de tratamento.

\section{Malva}

A Malva sylvestris L., conhecida popularmente como Malva, possui efeito farmacológico devido à presença de flavonoides e mucilagens, eficaz para uso tópico em processos inflamatórios da boca e garganta, bem como, antisséptico da cavidade oral auxiliando no combate de bactérias e fungos e age como calmante no local das ulceraçóes. As partes da planta utilizadas são suas folhas e flores. As folhas são utilizadas tanto na forma de decocção e infusão, como vapor, xarope, maceração, e na produção de pomadas 17,33 .

Há estudos que demonstram a atividade anti-inflamatória da Malva, com a aplicação tópica de extrato etanólico das folhas de malva em camundongos, o qual acarretou em redução do inchaço, inchaço este, induzido por éster de forbol, que liberam ácido araquidônico e causam secreção de prostaglandinas, o influxo de polimorfonucleares e os níveis de interleucina-1beta no tecido ${ }^{34,35}$.

Outro estudo, descreve a aplicação do extrato etanólico das folhas de Malva, em modelo semelhante de inflação, ocasionada por óleo de cróton em camundongos, reduziu o edema em $21 \%{ }^{36}$. A eficácia na ação anti-inflamatória também foi descrita com a aplicação de creme na pata inflamada de ratos, creme este, preparado a partir da decocção das folhas e flores de malva ${ }^{37}$.

Ainda, o extrato etanólico das flores e folhas reduziu em $80 \%$ a formação de óxido nítrico $(\mathrm{NO})$, sendo $\mathrm{NO}$ o mecanismo responsável pela maioria dos processos 
inflamatórios e autoimunes, e também ocasionou redução da quantidade da citocina (regula reaçáo imunológica e inflamatória) interleucina-1 e fator de necrose tumoral-alfa induzidos por lipopolissacarídeo de bactéria em células fibroblastos 3T3 de camundongos 38,39. Estudos utilizando partes aéreas da planta preparadas por decocçáo inibiram em 25 $\pm 5 \%$ a atividade da acetilcolinesterase, porém, o extrato etanólico não alterou a atividade da enzima ${ }^{40}$.

As folhas da malva, também apresentaram efeito cicatrizante na formulação com pomadas, aplicada em feridas na pele de ratos diabéticos, a avaliação histológica do tecido tratado com malva obtido nos dias 9 e 18 após a lesáo mostrou aumento nas fibras bem organizadas de colágeno, mais fibroblastos e poucas células inflamatórias quando comparado com tecidos não tratados ${ }^{41}$.

Não há dados na literatura dados sobre toxicidade da malva. Não possuindo contraindicaçóes e efeitos adversos relatados no uso da malva, sendo importante ressaltar o cuidado com uso em crianças, gestantes e idosos, devido à ausência de estudos em relaçáo a toxicidade ${ }^{42}$.

\section{Camomila}

A Matricaria chamomilla L., conhecida popularmente como Camomila, possui flavonóides e taninos, sendo utilizado nas preparaçôes as inflorescências, partes aéreas e folhas ${ }^{17,21}$. Sua ação anti-inflamatória potente ocorre devido às suas lactonas e flavonóides, óleo essencial (alfa bisabolol) e cumarinas ${ }^{33}$.

O alfa bisabolol compóem características antiflogísticas, antibacterianas, antimicóticas e protetora de mucosas agindo assim contra úlcera. A atividade espasmolitica musculotrópica corresponde a da papaverina. Outros princípios ativos também apresentam propriedades espasmolitica como os flavonóides e as cumarinas alem de efeito inibitório do crescimento de certos microorganismos. Os esteróides são importantes para o processo anti-inflamatório auxiliando a liberação de hormônio adrenocorticotrófico (ACTH) a nível supra- renal ${ }^{43}$.

Os flavonóides não são apenas adsorvidos pela superfície da pele após aplicação cutânea, mas penetram nas camadas mais profundas da pele, o que é importante para seu uso como antiflogístico.

Deve-se ter cuidados no uso da camomila em casos de reaçôes alérgicas que ocorrem em contato com capítulos florais. Há alguns sintomas que os pacientes podem apresentar como dermatites de contato ${ }^{44}$.

Atualmente há no mercado farmacêutico alguns medicamentos que contem camomila em sua composição como, o Colutóide camomila, o qual é utilizado para o auxílio no processo de cicatrização de feridas na mucosa bucal, em forma de gel, é composto por extrato seco de Matricária chamomilla L. que é o princípio ativo, o mesmo 
é incorporado aos excipentes hipromelose (agente espessante), metilparabeno com ação antimicrobiana, propilparabeno como conversante antimicrobiano, sacarina sódica afim de conferir sabor doce, dimeticona (silicone), propilenoglicol na ação emoliente, aroma e água deionizada com veículo ${ }^{19,23}$.

\section{CONSIDERAÇÓES FINAIS}

Com etiologia ainda desconhecida, as estomatites aftosas são alvo de muitas teorias em relação a seu fator desencadeante. Com o presente trabalho foi possível avaliar a importância do cuidado farmacêutico, tanto no aconselhamento do paciente ao encaminha-lo ao médico, como na indicação de medicamento em casos de aftas bucais de aparição súbita e recente, em sujeito sadio, visando sempre assegurar o acesso da população aos medicamentos a partir da promoção e do uso correto dos mesmos, tornando-se possível também avaliar que apesar da teoria do complexo autoimune ser a hipótese mais significativa, há fatores como hereditariedade, traumas, deficiência de vitamina B12 e ingestão de certos alimentos que também desencadeiam o aparecimento.

A prevenção mostrou-se essencial e prática. Nos medicamentos destaca-se o Flogoral $^{\otimes}$ devido suas três ações farmacológicas, a anti-inflamatória, analgésica e anestésica bucal. A malva e a camomila apresentam-se eficazes, tornando-se uma alternativa simples e acessível para todas as classes sociais, sendo de grande importância para a população receber essas informaçóes a respeito das plantas e seu modo de preparo.

\section{REFERENCIAS}

1. Finkel R, Pray WS. Guia de dispensação de produtos terapêuticos que não exigem prescrição. 2a ed. Artmed Editora; 2007.

2. Souza PRM. Prevalêcia e fatores associados à herpes labial recorrente e às aftas orais recorrentes em adolescentes do sexo masculino alistandos do exército da cidade de pelotas [tese]. Pelotas: Universidade Católica de Pelotas; 2016.

3. Saavedra JAP, Jimenes FNP. Estomatitis aftosa recurrente: actualización. Rev Cubana Estomatol. 2005 Jan-Abr; 42(1).

4. Miziara ID. O tratamento da estomatite aftóide recorrente ainda intriga. Rev Assoc Med Bras. 2009; 55(2).

5. Vieira JLKF. Tratamento e manejo de pacientes com úlceras aftosas recorrentes: uma revisão sistemática [trabalho de conclusão de curso]. Natal: Universidade Federal do Rio Grande do Norte; 2017. 
6. Filho JAX, Miziara ID. Estomatite aftóide recorrente: atualização no tratamento. Arq Fund Otorrinolaringol. 2001; 5(4).

7. Costa GF, Castro JFL. Etiologia e tratamento da estomatite aftosa recorrente: revisão de literatura. Rev Med. [Internet]. 2013; 46(1). Acesso em: 05 de abr de 2018. Disponível em: < http://revista.fmrp.usp.br/2013/vol46n1/REV_Etiologia\%20e\%20 tratamento $\% 20 \mathrm{da} \% 20$ estomatite\%20aftosa\%20recorrente $\% 20-\% 20$ revis\%E3o\%20 de\%20literatura.pdf>.

8. Hodosh, M. Method for treating canker sores. Disponível em: https://patents. google.com/patent/US4191750A/en \&gt. Acessado em 22 de abr de 2018.

9. Consolaro A, Consolaro MFM-O. Aftas após instalação de aparelhos ortodônticos: porque isso ocorre e protocolo de orientaçóes e condutas. R Dental Press Ortodon Ortop Facial. [Internet] 2009 Jan-Fev; 14(1):18-24. Acesso em: 25 de abr de 2018. Disponível em: < http://www.scielo.br/pdf/dpress/v14n1/v14n1a03.pdf>.

10. Fraiha PM, Bittencourt PG, Celestino LR. Estomatite aftosa recorrente. Rev Bras Otorrinolaringol [Internet]. Rio de Janeiro: 2002; 68(4):571-578. Acesso em: 05 de mai de 2018. Disponível em: < http://www.scielo.br/scielo.php?pid=S003472992002000400019\&script=sci_abstract\&tlng=pt $>$.

11. Crespo MR, Martínez AB. Aftas de la mucosa oral. Av Odontoestomatol [Internet]. Madrid; 2011; 27(2):63-74. Acesso em: 15 de mai de 2018. Disponível em: http:// scielo.isciii.es/pdf/odonto/v27n2/original1.pdf.

12. Boa Saúde. Aftas Bucais: tipos, diagnósticos e conselhos para aliviar a dor. 2016. Disponível em: <http://www.boasaude.com.br/artigos-de-saude/3197/-1/aftas-bucaistipos-diagnosticos-e-conselhos-para-aliviar-a-dor.html>. Acesso em: 20 de mai de 2018.

13. Marques LAM. Atenção farmacêutica em distúrbios menores. 2a ed. Medfarma; 2008.

14. Consulta Remédios. Bula do Albicon. Acesso em: 25 de mai de 2018. Disponível em: < https://consultaremedios.com.br/albicon/bula>.

15. Ache. Bula de medicamento. 2014. Acesso em: 30 de mai de 2018.

Disponível em: < http://www.anvisa.gov.br/datavisa/fila_bula/frmVisualizarBula. asp?pNuTransacao=5659292014\&pIdAnexo=2123329>.

16. Pinto LMA. Interação dos anestésicos locais: benzocaína, lidocaína e tetracaína com membranas modelo [dissertação]. Campinas, SP: Universidade Estadual de Campinas; 1998.

17. Brasil. Agência Nacional de Vigilância Sanitária. $1^{\text {a }}$ ed. Formulário de Fitoterápicos da Farmacopéia Brasileira. Brasília: Anvisa; 2011. Disponível em: https://www.saude. 
gov.br/images/pdf/2014/julho/14/Formulario-de-Fitoterapicos-da-FarmacopeiaBrasileira-sem-marca.pdf. Acesso em: 31 de mai de 2018.

18. Brandão ACC. Farmacotécnica: Excipientes e Adjuvantes Farmacotécnicos. Acesso em: 01 de jun de 2018. Disponível em: < http://boaspraticasfarmaceuticas.blogspot. com/2012/05/farmacotecnia-excipientes-e-adjuvantes.html>.

19. Bulário. Bula do Albocresil. Acesso em: 26 de mai de 2018. Disponível em: < https://www.bulario.com/albocresil/>.

20. Medicinanet. Acesso em: 26 de mai de 2018. Disponível em: < https://www. medicinanet.com.br>.

21. Brasil. Ministério da Saúde. Secretaria de Ciência, Tecnologia e Insumos Estratégicos. Cuidado farmacêutico na atenção básica; caderno 1. Brasília, DF: Ministério da Saúde; 2015. Acesso em: 26 de mai de 2018. Disponível em: <https:// bvsms.saude.gov.br/bvs/publicacoes/servicos_farmaceuticos_atencao_basica_saude. pdf>.

22. Giacomini A et al. Perfil hematológico e níveis de vitamina B12, ferro e ácido fólico de pacientes com ulceração aftosa recorrente. RFO [Internet]. 2010 Jan-abr; 15(1):710. Acesso em: 30 de mai de 2018. Disponível em: < http://revodonto.bvsalud.org/pdf/ rfo/v15n1/02.pdf >.

23. Oliveira ARMD. Abordagem Diagnóstica da Aftose Oral Recorrente [dissertação]. Porto: Universidade do Porto; 2013. Disponível em: <https://repositorio-aberto.up.pt/ bitstream/10216/71912/2/30998.pdf>. Acesso em: 29 de mai de 2018.

24. Lima R. Aftas: Alimentos a Evitar para não Agravar a Dor. Acesso em: 29 de mai de 2018. Disponível em: < http://www.vidaativa.pt/a/aftas-alimentos-a-evitar/>.

25. Boidy J. Como Evitar as Aftas. Acesso em: 01 de jun de 2018. Disponível em: $<$ https://pt.wikihow.com/Evitar-as-Aftas $>$.

26. Júnior IF et al. Analgesia tópica com policresuleno e cinchocaína no pós-operatório de hemorroidectomias: um estudo prospectivo e controle. Rev Col Bras Cir [Internet]. 2014; 41(2): 092-099. Acesso em: 30 de mai de 2018. Disponível em: <http://www. scielo.br/pdf/rcbc/v41n2/pt_0100-6991-rcbc-41-02-00092.pdf>.

27. Curso avançado sobre tratamento de feridas. Acesso em: 01 de jun de 2018. Disponível em: <file://C:/Users/User/Downloads/CURSO_AVANCADO_NO_ TRATAMENTO_DE_FERIDAS_(BuscAtiva).pdf>.

28. Carvalho MVH et al. Agentes homostáticos locais e adesivos teciduais. Rev col Brás Cir [Internet]. 2013; 40(1): 066-071. Acesso em: 29 de mai de 2018. Disponivel em: < http://www.scielo.br/pdf/rcbc/v40n1/12.pdf>. 
29. Takeada Pharma Ltda. Produtos Takeda. Acesso em: 30 de mai de 2018. Disponível em: <https://www.takeda.com/pt-br/o-que-fazemos/produtos/>.

30. Cerqueira GS et al. Aspectos toxicológicos da Benzidamina. Rev Inter [Internet]. 2014; 7(2): 05-16. Acesso em: 02 de jun de 2018. Disponível em: < http://www. repositorio.ufc.br/bitstream/riufc/10263/1/2014_art_gscerqueira.pdf>.

31. Sarveiya V, Templeton JF, Benson HA. Effect of lipophilic counter-ions on membrane diffusion of benzydamine. Eur J Pharm Sci, 2005; 26(1), 39-46. Acesso em: 02 de jun de 2018. Disponível em: < https:/www.sciencedirect.com/science/article/ abs/pii/S0928098705001375>.

32. Guertler AT, Pearce WA. A Prospective Evaluation of Benzocaine-Associated Methemoglobinemia in Human Beings. Ann Emerg Medic. 1994; 24(4), 626-630. Acesso em: 02 de jun de 2018. Disponível em: < https://pubmed.ncbi.nlm.nih. gov/8092589/>.

33. Saludes. Manzanilla comun (matricaria chamomilla). 2003. Acesso em: 08 de mai de 2018. Disponível em: <http://salud.es/medicamento/manzanilla-comun-matricariachamomilla/>.

34. Evans FJ, Edwards MC. Activity Correlations in the Phorbol Ester Series. Bot J Linn Soc [Internet]. 1987. 94: 231-246. Acesso em: 08 de mai de 2018. Disponível em: < https://onlinelibrary.wiley.com/doi/abs/10.1111/j.1095-8339.1987. tb01048.x>.

35. Prudente AS, Loddi AMV, Duarte MR, Santos ARS, Pochapski MT, Pizzolatti MG, et al. Pre-clinical anti-inflammatory aspects of a cuisine and medicinal millennial herb: Malva sylvestris L. Food and Chemical Toxicology [Internet]. 2013; 58:32431. Acesso em: 08 de mai de 2018. Disponível em: < https://pubmed.ncbi.nlm.nih. gov/23684757/>.

36. Conforti F, Sosa S, Marrelli M, Menichini F, Statti GA, Uzunov D, et al. In vivo anti-inflammatory and in vitro antioxidant activities of Mediterranean dietary plants. Journal of Ethnopharmacology [Internet]. 2008; 116(1):144-51. Acesso em: 08 de mai de 2018. Disponível em: < https://pubmed.ncbi.nlm.nih.gov/18164564/>.

37. Chiclana CF, Enrique A, Consolini AE. Topical anti-inflammatory activity of Malva sylvestris L. (Malvaceae) oncarragenin-induced edema in rats [Internet]. 2009; 28(2): 275-8. Acesso em: 08 de mai de 2018. Disponível em: < https://www. researchgate.net/publication/289233029_Topical_antiinflammatory_activity_of_ Malva_sylvestris_L_Malvaceae_on_carragenin-induced_edema_in_rats>.

38. Šarić-Kundalić B, Dobeš C, Klatte-Asselmeyer V, Saukel J. Ethnobotanical survey of traditionally used plants in human therapy of east, north and northeast Bosnia and 
Herzegovina. J Ethnopharmacol [Internet]. 2011; 133(3):1051-76. Acesso em: 08 de mai de 2018. Disponível em: <https://pubmed.ncbi.nlm.nih.gov/21094241/>.

39. Filho RF, Zilberstein B. Óxido nítrico: o simples mensageiro percorrendo a complexidade. Metabolismo, síntese e funçóes. Rev Ass Med Bras São Paulo. 2000 JulSet. 46(3):265-71. Acesso em: 06 de jun de 2018. Disponível em: http://www.scielo.br/ scielo.php?script=sci_arttext\&pid=S0104-42302000000300012.

40. Ferreira A, Proença C, Serralheiro MLM, Araújo MEM. The in vitro screening for acetylcholinesterase inhibition and antioxidant activity of medicinal plants from Portugal. J Ethnopharmacol [Internet]. 2006. 108(1):31-37. Acesso em: 06 de jun de 2018. Disponível em: < http://esa.ipb.pt/pdf/RefPlants_13.pdf>.

41. Pirbalouti AG, Azizi S. Wound healing activity of Malva sylvestris and Punica granatum in alloxan-induced diabetic rats. Acta Pol Pharm. 2010. 67(5):511-6. Acesso em:. 06 de jun. de 2018. Disponível em: < https://www.ncbi.nlm.nih.gov/ pubmed/20873419>.

42. Sponchiado G. Avaliaçáo da eficácia e segurança do extrato da Malva sylvestris com potencial atividade para tratamento de disfunçáo da pele [tese]. Curitiba, 2015. Acesso em 01 de jun de 2018. Disponível em: <http://portalarquivos2.saude.gov.br/images/ $\mathrm{pdf} / 2017 /$ setembro/11/Monografia-Malva.pdf>.

43. Cardoso JL. Camomila. Acesso em: 08 de jun de 2018. Disponível em: < http:// www.uepg.br/fitofar/dados/camomila.pdf>.

44. Hessel F, et al. Uso da camomila para o tratamento de afecção de garganta. 2014. Acesso em: de jun de 2018. Disponível em: <http://www.saocamilo-sp.br/novo/ eventos-noticias/saf/resumo-32.pdf>.

Autor Correspondente: Layza Kowalski

E-mail: layzakowalski@hotmail.com

Recebido em: 2020-02-11

Aprovado em: 2020-05-22 